\title{
Boriding of steel surface with beams of boron atoms
}

\author{
Yuri F. Migal* and Andrey V. Sidashov \\ Rostov State Transport University, 344038 Rostov-on-Don, Russia
}

\begin{abstract}
We consider a new method for hardening the steel surface, which differs from the known CHT boriding method in the possibility of creating a surface with a lower fragility. Within this approach, the boriding is carried out by treating the steel surface with atomic beams of boron at a temperature below $750{ }^{\circ} \mathrm{C}$. In this case, a friable layer of pure boron appears on the outer surface of the steel. Then, boron atoms diffuse from this layer into the surface layers of the steel. To detect boron in a steel sample, we used the X-ray photoelectron spectroscopy method. With its help we have obtained spectra of both the outer surface of a steel sample and surface layers at depths up to $8 \mathrm{~nm}$. The spectra of the surface layers showed that as a result of boriding in the sample there appeared the boron in the zero oxidation state. This fact is consistent with the notion that, in the case of a small concentration of boron, it is located on the boundaries between the grains in the surface layer of steel and strengthens the bonds between the boundaries.
\end{abstract}

\section{Boriding of steel surface}

The boriding of the metal surface is one of the known methods to improve the properties of metals. When boriding of steel many characteristics of its surface are improved, including hardness, wear resistance, corrosion resistance, surface tension etc. At present, the method of chemical heat treatment (CHT), first proposed by Chizhevsky [1], is widely used. In accordance with this method, a set of substances including boron-containing compounds is applied to the surface of steel samples. This procedure is carried out at temperatures above $800{ }^{\circ} \mathrm{C}$ and for a time of about 4 hours. Under such conditions boron diffuses into the surface layers of steel. As a result, the surface of the samples is saturated with boron and it becomes more durable. The disadvantage of this approach consists in increasing the fragility of the surface, which is undesirable in the case of rapidly changing mechanical loads (for example, under shock loads).

The cause of the increased fragility is the formation of $\mathrm{Fe}$ and $\mathrm{Fe}_{2} \mathrm{~B}$ iron borides in surface layers of steel [2]. In order to avoid the appearance of the borides, the surface should be treated at $t<800{ }^{\circ} \mathrm{C}$. Recently we studied one of the options for low-temperature CHT boriding [3]. It was found that in the treatment regime at $t \sim 700-750{ }^{\circ} \mathrm{C}$ for 25 hours (instead of 4 hours with standard CHT boriding) the boron concentration in the surface

\footnotetext{
*Corresponding author: ymigal@mail.ru
} 
layers of steel remains excessively low. This does not make it possible to increase essentially the wear resistance of steel.

In this connection, there is a need to search for more efficient ways of low-temperature boriding. One of such ways, as we believe, is surface treatment by using beams of boron atoms.

\section{Boriding with beams of boron atoms}

Below we report on results of the study of chromium steel samples, which previously were exposed to beams of boron atoms, according to the scheme described in [4]. These samples were prepared by a group of scientists from TUSUR University (Tomsk) as follows. In a special chamber with low pressure, a stream of electrons is created that bombard the workpiece from crystalline or amorphous boron. The boron ions $\mathrm{B}_{2}^{+}$emitted from this workpiece are directed by a specially created magnetic field to the previously prepared flat surface of a steel sample. Landing on this surface, boron ions create a certain layer of friable substance, where ions, due to the interaction with the metal surface, lose their charge. Then already neutral boron atoms diffuse from this layer into the surface layers of steel. Since the temperature of this process is small (it is clearly less than $800{ }^{\circ} \mathrm{C}$ ), it should be expected that $\mathrm{Fe}$ and $\mathrm{Fe}_{2} \mathrm{~B}$ compounds that embrittle the steel surface will not appear in the surface layer.

\section{Analysis of elemental composition and compounds formed in surface layers of steel}

The most important task of our study is to confirm the penetration of boron into steel under the given conditions. To detect the boron atoms in a steel sample, we used the X-ray photoelectron spectroscopy (XPS) method [5]. This method allows us to fix the formation or absence of chemical bond between components of a sample of polycrystalline material and diffused boron atoms. The study was carried out by using the surface analysis system SPECS [6] with monochromatization of the X-ray emission of the AlK $\alpha$ line with energy of $1486.6 \mathrm{eV}$. The vacuum at recording was no worse than $8 \cdot 10^{-8} \mathrm{~Pa}$. The charge of the sample was estimated by using $1 \mathrm{~s}$ spectra of carbon from natural hydrocarbon contaminations on the surface.

The initial object was a disk of chromium steel, one of whose surfaces was treated with a beam of boron ions according to the scheme described above. A sample was cut from the disk that was then placed in the chamber. The section of the sample was analyzed, which surface was a rectangle with dimensions of $1 \mathrm{~mm} \times 10 \mathrm{~mm}$. Ion etching was initially carried out, which removed hydrocarbon contaminants, hydroxyl, oxygen groups and partially adsorbed oxygen from the investigated surface. Such etching is necessary to obtain sufficiently contrast X-ray lines of elements belonging to steels.

When obtaining the spectra, the energy scanning step was $0.1 \mathrm{eV}$. The energy resolution at the selected operating mode was estimated by using the internal $3 \mathrm{~d}_{3 / 2}$ line of silver and it amounted to $0.45 \mathrm{eV}$.

Fig. 1a shows the spectrum of the external surface of the sample after cleaning. From this spectrum it follows that on the surface there are oxidized iron, oxygen, carbon, sodium (binding energy $1072.5 \mathrm{eV}$ ) and boron. The B1s boron line consists of two components with binding energies of $187.7 \mathrm{eV}$ and $191.8 \mathrm{eV}$. The line with higher energy refers to the oxidized state, and the line with lower energy, according to [7], to the boron atom in the zero oxidation state.

To analyze the composition of modified layers at different depths we used ion profiling with $\mathrm{Ar}^{+}$ions. The accelerating voltage in the ion gun was $3 \mathrm{kV}$ at a current of $3 \mu \mathrm{A}$. The 
pressure in the sample preparation chamber of the spectrometer during ion etching was $5 \cdot 10^{-3} \mathrm{~Pa}$. The rate of removing surface layers by an ion beam was approximately $3 \AA / \mathrm{min}$. Spectra were obtained for layers with depths $h=2,4,6$ and $8 \mathrm{~nm}$.
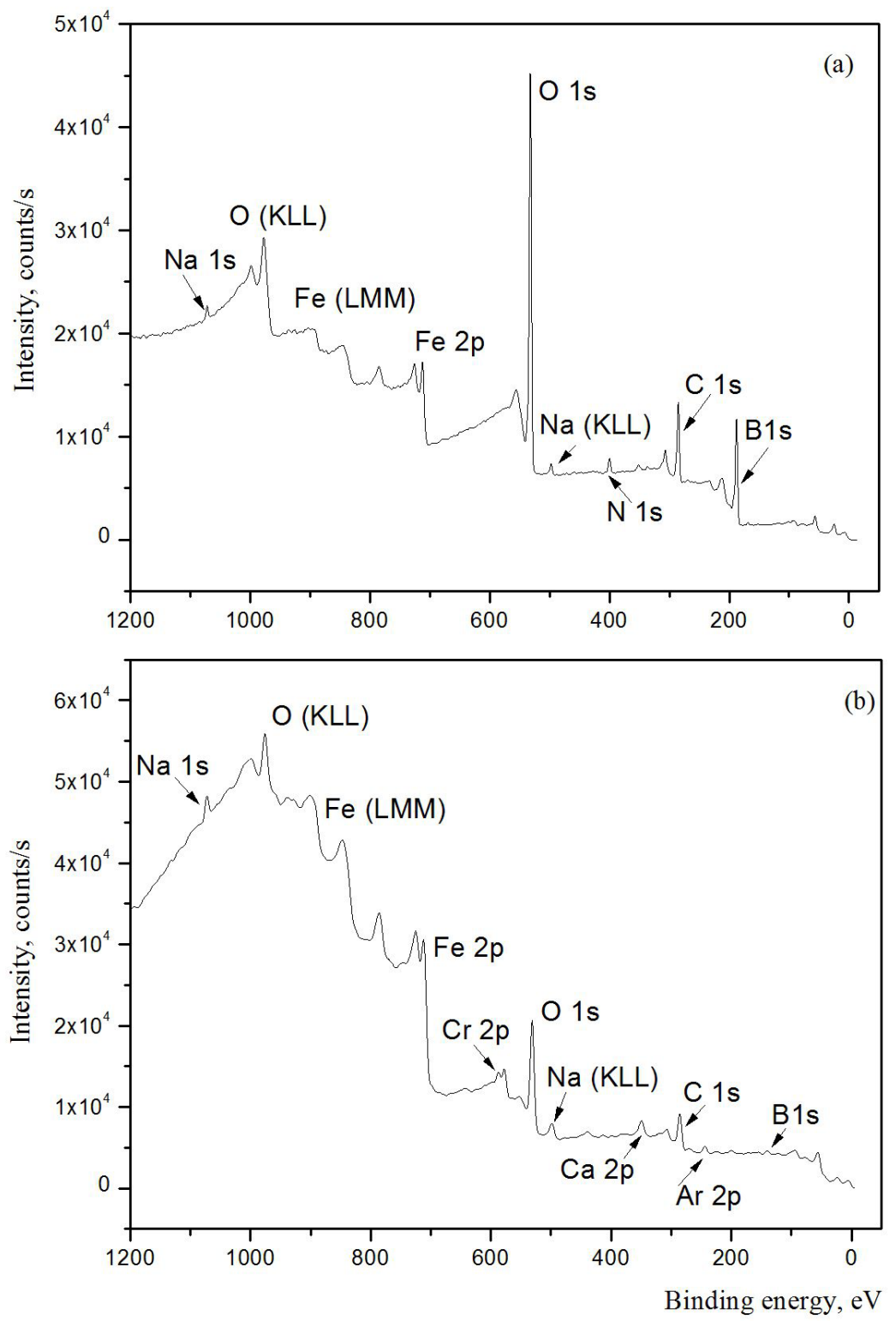

Fig. 1. Overview X-ray photoelectron spectra of a sample of chromium steel, the surface of which was treated with a beam of boron ions. (a) the spectrum of the free (external) surface;

(b) the spectrum of the inner layer of the surface at a depth of $6 \mathrm{~nm}$.

The conducted studies showed the following results (Fig. 1b). The composition of the modified surface at almost all depths is represented by iron atoms in the oxidized state (binding energy $\sim 710.5 \mathrm{eV}$ in the $\mathrm{Fe}_{2} \mathrm{O}_{3}$ compound) and atoms in zero oxidation state 
(binding energy $\sim 707 \mathrm{eV}$ ), as well by oxygen and carbon atoms with binding energies of $\sim 531.4$ and $285 \mathrm{eV}$, respectively.

The most important for us result is the fact that at depths up to $\mathrm{h}=6 \mathrm{~nm}$ boron is fixed with zero degree of oxidation (binding energy $\sim 187.7 \mathrm{eV}$ ). Obviously, this is the boron that penetrated into the steel sample as a result of diffusion. The concentration of boron decreases with increasing depth, and at $h=6 \mathrm{~nm}$ its content is comparable to the sensitivity limit of the device. In contrast, the concentration of chromium oxide at a depth of $2 \mathrm{~nm}$ is zero, but it increases with $\mathrm{h}$ increasing. This separation of boron and chromium oxide in the surface layers of steel suggests that the penetration of boron to a greater depth in the chromium steel is inhibited by chromium oxide.

At the present time, we study the tribological characteristics of borated samples.

\section{Conclusions}

Comparing the spectra of the outer (free) surface of a steel sample subjected to the action of atomic beams of boron and the surface layers of this sample at depths of up to $8 \mathrm{~nm}$, we conclude that as a result of surface treatment of steel with atomic beams of boron, boron diffusion into the surface layers occurred. The presence of nonoxidized boron in this region agrees with the notion that in the case of a small concentration of boron, its atoms are located on the boundaries between grains in the surface layer of steel [3]. It is significant that there are no lines in the spectra of surface layers indicating the presence of boron compounds with iron ( $\mathrm{FeB}$ and $\left.\mathrm{Fe}_{2} \mathrm{~B}\right)$, which increase the fragility of steel [2].

This work is supported by the Russian Science Foundation under grant 16-19-10467 performed in Rostov State Transport University.

\section{References}

1. N.P. Chizhevski, J. Rus. Metall. Soc. 4(19), 645 (1915) (in Russian)

2. H. Kunst, B. Haase, J. C. Malloy, K. Wittel, M. C. Nestler, A. R. Nicoll, U. Erning, G. Rauscher, Metals, Surface Treatment. In Ullmann's Encyclopedia of Industrial Chemistry (Wiley-VCH, 2006)

3. Yu.F. Migal, V.I. Kolesnikov, In book: PHENMA 2017. Chapter 8 (2018)

4. Y.G. Yushkov, A.V. Tyunkov, E.M. Oks, D.B. Zolotukhin, J. Appl. Phys., 23 (120), $233302(2016)$

5. C.D.Wagner, W.M. Riggs, L.E. Davis, J.F. Moulder, G.E. Muilenberg, Handbook of Xray photoelectron spectroscopy (Minnesota, 1978)

6. SPECS Surface Nano Analysis GmbH S, http://www.specs.com

7. C.W. Ong, H. Huang, J. Appl. Phys., 7 (95), 3527 (2004) 